\title{
MIRANDO HACIA FINISTERRE: EL COMERCIO FENICIO EN LA FACHADA NOROCCIDENTAL DE LA PENÍNSULA IBÉRICA
}

\author{
Juan Antonio Martín Ruiz \\ Universidad Internacional de Valencia
}

\begin{abstract}
Resumen: Se examinan los contactos establecidos entre los colonizadores fenicios y las comunidades célticas asentadas en el noroeste de la Península Ibérica durante el I milenio a.C. Aunque valorada sólo recientemente, lo cierto es que la influencia oriental en esta zona parece ser más importante de lo que hasta no hace mucho se había venido considerando, como evidencian los cada vez más numerosos hallazgos realizados que cabe situar temporalmente sobre todo a partir del siglo VI a.C. y que continúan hasta la anexión de estos territorios por Roma.
\end{abstract}

Palabras clave: comercio, fenicios, celtas, Círculo del Estrecho, Galicia.

\section{Looking towards Finisterre: the Phoenician trade in the north-western façade of the Iberian Peninsula}

Abstract: The contacts established between the Phoenician colonisers and the Celtic communities settled in the northwest of the Iberian Peninsula during the 1st millennium BC are examined. Although only recently assessed, the fact is that eastern influence in this area seems to have been more important than had been considered up to now, as evidenced by the increasingly numerous findings that can be chronologically placed especially after the 6th century $\mathrm{BC}$, and that continue until the annexation of these territories by Rome.

Key words: trade, Phoenicians, Celtic, the Straits of Gibraltar Circle, Galicia.

\section{INTRODUCCIÓN}

Hace ya varios siglos que se ha venido planteando la posible presencia de navegantes fenicios en la vertiente noroccidental de la Península Ibérica, para lo que los investigadores centraron su atención en la búsqueda de topónimos que pudieran probarlo o bien presentando una serie de restos materiales que se atribuían a dicha presencia, como se afirmaba lo eran diversos elementos constructivos de Estaca de Bares o algún altar hallado en La Peña de Rodas (Maciñeira Pardo, 1896: 123 y 126). Sin embargo, la falta de apoyo arqueológico al ser considerados como elementos propios del mundo romano hacía más

Data de recepció: 26 de juny de 2018 / Data d'acceptació: 24 de juliol de 2018. 
que difícil para la comunidad científica aceptar tal afirmación, y ello a pesar de que no se negaba que sus navíos hubieran surcado unas aguas tan septentrionales (Hübner, 1902: 552-553).

En realidad esta presencia fenicia había atraído la atención de los estudiosos, particularmente en relación con el comercio del estaño y la localización de las misteriosas islas Casitérides de donde estos intrépidos navegantes obtenían este preciado metal (López Pardo, 2000: 42-44). En consecuencia, ya desde el siglo XVIII se postuló su ubicación en las costas gallegas (Cornide de Folgueira, 1790: 5-14; Jáuregui, 1952: 31), aunque con el paso del tiempo este interés se fue perdiendo hasta llegar a dudarse que los fenicios se desplazaran a este lugar. Máxime al considerar que lo habrían conseguido en algún punto intermedio que debía estar situado en la zona de río Duero (Alvar Ezquerra, 1980: 479), aun cuando a tenor de los recientes hallazgos efectuados en el área galaica que iremos examinando en las páginas que siguen, nada excluye que lo obtuviesen en el territorio galaico.

Ahora bien, lo cierto es que tras décadas de olvido esta creencia se ha visto confirmada en los últimos años por la aparición de un importante número de hallazgos, si bien también es preciso reconocer que para ello ha sido necesario vencer cierta reticencia académica que tiene su origen en motivaciones de carácter ideológico muy arraigadas, al considerar que estos contactos podían menoscabar la "pureza" de lo "céltico", circunstancia que desde su óptica vendría a representar una disminución de la importancia que desde determinados planteamientos se otorgaba a la supremacía que este último componente poblacional ejerció en estas latitudes políticas (Ruiz Zapatero, 2003: 220-235; Domínguez Pérez, 2005b: 36-37).

A ello debemos sumar la confusión que no pocas veces ha existido entre los investigadores a la hora de valorar correctamente muchos de los restos materiales que han ido apareciendo (Paz Virvet, 2016: 128 y 131), al ser adscritos al mundo romano como ha acontecido en más de una ocasión con las cerámicas áticas de barniz negro que de forma errónea han sido consideradas como vasos campanienses, o con los fragmentos de recipientes anfóricos y ungüentarios de pasta vítrea que se han situado desde el punto de vista temporal en fechas bastante más modernas de las que en realidad les correspondía (Hidalgo $\mathrm{Cu}$ ñarro, Peña Santos, 2000: 807; González Ruibal et alii, 2010: 577-578).

Como decimos, y a pesar de que los importantes descubrimientos dados a conocer en los últimos años en las desembocaduras de los ríos Guadiana, Tajo y Mondego propiciaron el que algunos autores postulasen que la presencia fenicia debía quedar limitada al sur de este último cauce fluvial (Pellicer Catalán, 1998: 256; Millán León, 1998: 160; Arruda, 2002: 254 y 257), lo cierto es que el panorama ha comenzado a cambiar sustancialmente, por lo que quizás sea necesario empezar a replantearse la bondad de esta pretendida frontera fluvial o si, por el 
contrario, la presencia de las comunidades de origen oriental instaladas en el denominado Círculo del Estrecho pudo llegar a latitudes más septentrionales de lo que suponíamos, con las implicaciones históricas que este hecho conlleva.

En consecuencia, cabe admitir que la presencia de hallazgos de clara raigambre fenicia o que, aun siendo elaborados en otros ámbitos culturales, fueron también comercializados por estos navegantes orientales en el antaño Finisterre, ha terminado por imponerse de manera que se abre un sugestivo mundo de contactos entre la vertiente atlántica noroeste y el mediodía peninsular, como demuestran los descubrimientos efectuados en diferentes yacimientos gallegos y asturianos. Así pues, creemos del mayor interés examinar estos contactos, así como el alcance que éstos pudieron tener a lo largo de varios siglos.

\section{LAS EVIDENCIAS MATERIALES DE LA INFLUENCIA FENICIA}

Gracias a los hallazgos realizados sabemos que los fenicios comercializaron una amplia variedad de productos aunque no siempre fueron fabricados por ellos como tendremos ocasión de comprobar. Además, no todos los atribuidos a estos navegantes son siempre fáciles de interpretar como acontece con un petroglifo situado en Auga dos Cebros en el que, junto a varias representaciones zoomorfas, se grabó un barco que mayoritariamente se ha valorado como oriental, bien con una cronología que comprende los siglos XIII-XII a.C. (Ruiz-Gálvez Priego, 2005), o fenicio de fecha posterior (Guerrero Ayuso, 2008: 85-86; Martín Ruiz, 2013: 39), y en el que se aprecian las cuadernas, una roda quizás con prótomo y un palo mayor con un posible toldo que protegería la cubierta de las inclemencias metereológicas.

Refiriéndonos a los materiales distribuidos por dichos navegantes en estos territorios es indudable que los más abundantes son obviamente los recipientes cerámicos, y en especial los anfóricos que en algún caso se ha propuesto pudieran llegar a fecharse en el siglo VII a.C. (Domínguez Pérez, 2006: 53), aun cuando las formas predominantes nos muestran recipientes adscribibles a los tipos Mañá-Pascual A4, Mañá C2b y del tipo Campamentos Numantinos destinados a servir de receptáculo a las salazones de pescado y que en algunos casos son claramente de origen gaditano, así como algún ejemplar de ánfora D1 de procedencia cartaginesa como podemos apreciar en los yacimientos de Bahía de La Coruña, Montealegre, A Forca, O Areal, Troña, Santa Trega y A Lanzada por citar tan sólo algunos ejemplos (González Ruibal et alii, 2007: 51-53; Domínguez Pérez, 2005a: 9; González Ruibal et alii, 2010: 582-583; Paz Virvet, 2016: 135).

Del mismo modo, se han hallado piezas que integran la vajilla de mesa pertenecientes al tipo Kouass que fueron fabricadas en talleres de la bahía de 
Cádiz, según vemos en puntos como Toralla o Punta de Muiño (Paz Virvet, 2016: 132), junto a platos pintados y de barniz rojo datables también entre los siglos IV-III a.C. que en más de una ocasión pudieran haber sido fabricados localmente como se ha sugerido para los descubiertos en A Lanzada (Suárez Otero, Fariña Busto, 1990: 327; Domínguez Pérez, 2005b: 32), si bien recientemente se ha planteado que en realidad no serían imitaciones hechas en tierras galaicas sino portuguesas (González Ruibal et alii, 2010: 584). Algo similar sucede en el castro Grande de Neixón con otros elementos cerámicos, tales como cuencos y jarras, que indudablemente imitan a vasos de sabor oriental (Ayán Vila et alii, 2008: 83-84), formas a las que podemos añadir los ungüentarios así como unos vasos que nos recuerdan vivamente a los pithoi fenicios (González Ruibal, 2006: 142). Todo ello sin olvidar algún askós ibicenco datado entre los siglos III-II a.C. de A Lanzada (González Ruibal, 2004a: 37-38), amén de fragmentos de otros de probable origen gaditano hallados en Monteagre (González Ruibal et alii, 2007: 64-65), o los fragmentos de jarras adscribibles al tipo ibicenco Eb. 64 (Ayán Vila et alii, 2008: 83).

Un problema lo constituía el fragmento cerámico hallado en el castro asturiano de Coaña que se había datado en el siglo III a.C., dado que hasta hace poco la cronología más antigua proporcionada por dicho yacimiento no sobrepasaba el siglo I d.C. (Camino Mayor, Villa Valdés, 2004: 54). Sin embargo, los datos facilitados por los análisis de Carbono 14 efectuados indican que dicho castro existía ya a mediados del I milenio a. C., por lo que desaparece cualquier distorsión cronológica (Camino Mayor, Villa Valdés. 2014: 211-213).

Junto estos hallazgos cerámicos se ha documentado la aparición de una serie de fragmentos de ungüentarios confeccionados en pasta vítrea en los castros Grande y Pequeño de Neixón, Castro das Ermidas, Valdamio y Chan da Brito, tratándose de piezas contenedoras de sustancias perfumadas que han sido fechadas entre los siglos VI a IV a.C. aun cuando algunos de ellos pueden alcanzar el siglo III a.C. (Domínguez Pérez, 2005b: 52-53; Ayán Vila et alii, 2008: 82-84; González Ruibal et alii, 2010: 584; Paz Virvet, 2016: 131).

Del mismo modo, es preciso comentar la aparición de cuentas de collar de pasta vítrea conocidas como "de ojos" que ofrecen un marcado sentido mágico y cuya cronología es parecida a la de los ungüentarios mencionados, los cuales se localizan en puntos como A Lanzada, castro da Forca, Neixón, Viladonga, Punta dos Prados, Santa Tegra, Castrovite, Montealegre o el castro asturiano de Lluis de Allande, siendo interesante constatar que es el tipo de hallazgo más habitual hasta el extremo de ser el único que aparece en asentamientos del interior (González Ruibal et alii, 2007: 50; González Ruibal, 2004a: 39; 2005: 140; Domínguez Pérez, 2005b: 50; Marín Suárez, 2007: 152; Parcero-Oubiña et alii, 2009: 91; González Ruibal et alii, 2010: 585; Pérez Pérez et alii, 2010: 
50-58; Paz Virvet, 2016: 133-134). Además, cabe hacer mención a una serie de monedas acuñadas en las cecas de Ebussus, Abdera y Gadir en Estaca de Bares (González Ruibal, 2004a: 39; 2005: 135; Domínguez Pérez, 2011: 298), apareciendo también estos numismas gaditanos en enclaves como Lugo, Santa Tegra, Pontevedra o Vivero (Alfaro Asins, 1988: 88-90).

Así mismo, debemos citar un fragmento de una posible terracota procedente del yacimiento de A Lanzada (González Ruibal, 2004a: 36; 2006: 140), que se ha propuesto sería similar a las localizadas en enclaves como Illa Plana en Ibiza o Bitia, además de un epígrafe encontrado en Monforte del que en verdad no sabemos mucho, el cual ha sido datado en el siglo III a.C. y en cuya superficie se grabó un texto en lo que parece fue una piedra utilizada como señalización para el que se ha propuesto como traducción la frase "no desplazar" (Fuentes Estañol, 1986: 30).

Como dijimos, también se ha planteado que los fenicios serían los responsables de la venta de otros productos no fabricados por ellos, como sucedería con algunas fíbulas localizadas en esta zona pertenecientes a los tipos Alcores, Adebuchal y doble resorte datables por tanto entre los siglos VII-VI a.C., encontradas en enclaves como Toralla, Montealegre o Coto da Pena (Paz Virvet, 2016: 136). En este apartado se incluirían también las cerámicas griegas de barniz negro y, en menor medida, figuras rojas fechables entre los siglos V-IV a.C., las cuales, aunque poco numerosas en general, muestran formas como olpes, aríbalos, copas, pelikes, cráteras de campana y platos de pescado junto a vasos de Gnathia y ánforas massaliotas y greco-itálicas, materiales que han sido recogidos en los castros de Forca, Recarca, Coto da Pena, Castromao, Neixón, Romariz, Santa Tegra, Alobre, Elvira, A Lanzada o Campa Torres en Gijón por no hacer demasiado prolija la enumeración (Coelho Ferreira da Silva, Mendes Pinto, 2001: 233; González Ruibal, 2004b: 299-300; González Ruibal et alii, 2010: 583; Domínguez Pérez, 2005b: 49; 2011: 294; Paz Virvet, 2016: 134). Todo ello sin que dejemos de lado algunos numismas helenos de los siglos V-IV a.C. acuñados en Atenas, Siracusa y Miriandros localizados en San Martinho de Anta y Serra do Pilar, muy cerca del límite entre Galicia y Portugal (Domínguez Pérez, 2005a: 10).

Otro tanto acontece con las cerámicas ibéricas recuperadas, entre las que podemos comentar la preferencia por los kalathos pintados, materiales bien documentados en los castros de Montealegre, Santa Tegra, A Lanzada, Vigo y Campa Torres en Asturias, que en no pocos casos habrían sido elaborados en el área catalana y levantina siendo así que incluso llegaron a ser imitados localmente (González Ruibal 2004a: 39; 2005: 141; González Ruibal et alii, 2007: 61-63). A ellos podemos sumar las ánforas turdetanas fechadas en el siglo II a.C. pertenecientes a los tipos Pellicer D y E, y que provienen de puntos como Santa Tegra y Montealegre (Millán León, 1998: 168; González Ruibal 
et alii, 2007: 62; Domínguez Pérez, 2005a: 9; 2011: 294), sin olvidar que también se conocen algunos numismas acuñados en cecas indígenas como Cástulo y Osset (Millán León, 1998: 187).

Por otro lado, se ha sugerido que buena parte de los materiales romanos de época republicana hallados en esta zona, especialmente los más antiguos, habrían sido igualmente comercializados por los fenicios (Millán León, 1998: 187-188; Ladra Fernández, 1999: 154). Tal acontecería con recipientes anfóricos como las Dressel I oriundas de alfares de Campania y Etruria, además de otras cerámicas localizadas en Montealegre, Santa Tegra, A Lanzada o Campa Torres (González Ruibal et alii, 2007: 54-58; González Ruibal, 2006: 140-141), las cuales incluirían formas como ollas, morteros, jarros y ungüentarios, amén de alguna que otra fuente de campaniense A y B en cantidades muy reducidas.

Otro elemento en el que también se ha detectado esta influencia mediterránea es la orfebrería galaica, sobre todo a partir de la realización de una serie de análisis efectuados a los torques que han determinado que estas piezas áureas tomaron como patrón para sus producciones un sistema ponderal de origen fenicio basado en el shekel, el cual se remontaría hasta el siglo VIII a.C. (Ladra Fernández, 1999: 149-153), lo que abre nuevas expectativas que deberán ser confirmadas con futuras investigaciones. Así, aunque hasta no hace mucho se consideraba que la fecha inicial de estas producciones no se remontaba más allá del siglo IV a.C. (Pérez Outeriño, 1989: 105; Almagro Gorbea, 2001: 163), estos estudios permiten elevar dichos contactos hasta una etapa aún no bien precisada pero que se remontaría a época arcaica, entre los siglos VIII y VI a.C. (Ladra Fernández, 1999: 145-154) y en la que se advierte la introducción no sólo de nuevas técnicas, casos del granulado y la filigrana, junto a motivos ornamentales como las rosetas o los gránulos, sino de alguna forma concreta como es la arracada (Castro Pérez, 1999: 375). Todo ello se percibe en diversos tipos de piezas como pueden ser, además de las arracadas ya comentadas, los collares articulados, las diademas y los torques (Pérez Outeriño, 1989: 96-98; Castro Pérez, 1999: 322-326), siendo así que inclusive se ha propuesto que algunos de estos collares articulados podrían ser obras de algún taller colonial (Pérez Outeriño, 1989: 96 y 98).

Otro indicio de índole metalúrgica que avalaría estos contactos es la aparición de algunos objetos de hierro, si bien en una cantidad muy reducida, que se datan a partir del siglo VII a.C., y que se han vinculado con la presencia de estos navegantes orientales quienes la introdujeron en la península, dado que la auténtica metalurgia de dicho metal no se desarrolla en este territorio hasta el siglo IV a.C. (Camino Mayor, Villa Valdés, 2014: 12).

Aunque los molinos rotativos de piedra para la trituración de cereales se extienden en época romana, es posible encontrar algunos ejemplares ya en el 
siglo IV o inclusive quizás en las últimas décadas del V a.C., como vemos en los castros de Forca y O Achadizo, cuya temprana introducción cabría atribuir a estos comerciantes orientales (Pérez Pérez et alii, 53-60).

Aun cuando quizás pueda parecer más sutil de percibir, también la evidencia arquitectónica documentada en algunos yacimientos, como Castro da Forca o A Lanzada, y que en este último ejemplo mencionado se remonta hasta los siglos V-IV a. C., parece mostrar una influencia oriental ya que se constata la existencia de algunas estructuras edilicias cuyas esquinas rematan en ángulo recto y que resultan del todo inusuales en el mundo indígena norteño, donde predomina de forma absoluta la planta circular (Suárez Otero, Fariña Busto, 1990: 316-317; Domínguez Pérez, 2005b: 51; González Ruibal, 2006: 132).

Ya para finalizar este apartado parece oportuno referirse a los betilos localizados en los castros de Alcabre, más conocido como Museo do Mar, y Toralla, si bien dada la trascendencia que este tipo de hallazgos tiene de cara a evaluar la posible existencia de contingentes poblacionales fenicios en estas latitudes volveremos a incidir más adelante sobre los mismos. Tres son los documentados en el primer punto aunque se ha sugerido que originariamente pudieran haber sido cuatro los existentes, betilos que han sido encontrados dentro de una estructura de planta rectangular datable entre finales del siglo $\mathrm{V}$ y comienzos del IV a.C., junto con lo que algunos han interpretado como un altar, mientras que en el segundo solamente se halló un betilo granítico (González Ruibal, 2004b: 298; 2006: 139; Suárez Otero, 2004: 40; Domínguez Pérez, 2006: 53; González Ruibal et alii, 2010: 590-591).

Todo ello sin olvidar que también se ha propuesto que en A Lanzada podría haber existido otro santuario del que tan sólo se habrían detectado los restos de una edificación rectangular (González Ruibal et alii, 2010: 591). A ello podemos añadir la aparición en el Castro Grande de Neixón de materiales y restos óseos de especies animales inusuales en el horizonte indígena integrada por un cochinillo, una gaviota y un perro, animal este último de marcado carácter religioso y funerario en el ámbito fenicio (Niveau de Villedary y Mariñas, 2008: 99-125; Grossi Mazzorin, 2008: 73), el cual ha sido valorado como un depósito votivo de carácter oriental (González Ruibal et alii, 2010: 592-593; Ayán Vila et alii, 2016: 200). Del mismo modo, se ha sugerido que una figurita de bronce con la representación de Hércules hallada en niveles de época romana del castro de Santa Tegra en Vigo podría ser un trasunto del culto al dios fenicio Melqart, cuyo sincretismo es bien conocido (González Ruibal, 2004a: 41; 2006: 140). 


\section{EL COMERCIO FENICIO EN EL FINISTERRE}

Para valorar en su justo término estos contactos resulta necesario tener en consideración la previa existencia de un Bronce Atlántico caracterizado por la metalurgia Vénant que ya desde el siglo IX, pero sobre todo desde el VIII a.C. hasta las primeras décadas de la siguiente centuria, puso en conexión el suroeste francés y la fachada atlántica con el mediodía peninsular y la isla de Cerdeña (Ruiz-Gálvez Priego, 1986: 12-23; Hidalgo, Peña, 2000: 809), ruta comercial que será aprovechada por los fenicios. En todo caso, vemos con seguridad a estos navegantes orientales ya desde el siglo VIII a.C. instalados a lo largo de la costa portuguesa, en una actividad comercial que con el curso de los siglos alcanzará también las tierras de la actual Asturias como reflejan los descubrimientos efectuados en los castros de San Luis (Suárez Otero, 2007: 152) y Campa Torres (González Ruibal et alii, 2007: 67-68).

Tomando como base el registro arqueológico que hemos repasado y alguna cita literaria podemos afirmar que los fenicios suministraron a estas comunidades productos manufacturados como pueden ser las cerámicas, ya sean éstas de elaboración propia o redistribuyendo vasos griegos o ibéricos aunque a veces en número reducido, algunos perfumes, collares de pasta vítrea, alimentos a juzgar con el contenido de los envases anfóricos y kalathos, así como probablemente algunos objetos de bronce y marfiles como el recuperado en Coimbra (Arruda, 2002: 250), a los que podemos citar otros cuyo rastro es mucho más difícil de seguir en el registro arqueológico, como es la sal según nos informa Estrabón (Geog., III, 5, 11) y a lo que quizás podríamos sumar las vestimentas.

Por su parte los fenicios obtendrían metales como se ha puesto de manifiesto para el cercano caso portugués (Arruda, 2002: 264-265), particularmente estaño y oro (Pérez Outeriño, 1989: 90; Millán León, 1998: 169; Guerrero Ayuso, 2009: 71; Paz Virvet, 2016: 129). En este sentido conviene recordar los hallazgos efectuados en el pecio de Bajo de la Campana que ha sido datado en el siglo VII a.C. y cuyo puerto de salida se ha sugerido fue la ciudad de Malaca o el Cerro del Villar, del que parte de su cargamento estaba integrado por lingotes de estaño que los análisis de isótopos realizados avalan proceden del noroeste peninsular (Mederos Martín, Ruiz Cabrero, 2004: 269; Polzer, 2014: 234). Así mismo, tampoco cabe descartar la adquisición de pieles de animales y esclavos, en tanto algunos autores (Fernández Uriel, 2000: 277) han apuntado a la posible comercialización por parte indígena del múrex con el que se obtenía tinte, la famosa púrpura destinada a la elaboración de prendas de vestir. 
Resulta interesante comprobar cómo las piezas imitadas se circunscriben a platos, cuencos, jarras, pithoi y algún que otro ungüentario, sin olvidar unos pocos ejemplos de kalathos ibérico. Ello contrasta vivamente con lo que acontece en el área tartésica en la que los alfareros indígenas elaboraron una amplísima gama de formas cerámicas de origen oriental y donde estas imitaciones ofrecen una mayor importancia tanto desde el punto de vista cuantitativo como cualitativo, si bien es mayor que el que podemos apreciar para la zona levantina peninsular, en la que casi exclusivamente se imitan pithoi y morteros trípodes (Ramón Torres, 2006: 205-206).

Podemos apreciar cómo en la zona galaica esta presencia fenicia se efectúa en una serie de yacimientos costeros ubicados en islas o penínsulas que controlan una importante vía de comunicación hacia el interior, como acontece con Castro da Forca en la desembocadura del río Miño, A Lanzada en la ría de Arousa, junto con Museo del Mar en la bahía de Vigo y, tal vez, el yacimiento asturiano de Campa Torres si nos atenemos al volumen y características de los restos allí recuperados. Son estos yacimientos, y particularmente Museo del Mar, los que acaparan la mayor parte de las importaciones fenicias puesto que el resto de yacimientos, situados ya al interior, proporcionan un volumen de materiales sensiblemente inferior que casi siempre queda reducido a la presencia de cuentas de collar de pasta vítrea. Así, parece factible considerar estos enclaves como centros redistribuidores de unos productos que, salvo en lo concerniente a las cuentas de pasta vítrea ya citadas, no alcanzan las áreas más interiores de Galicia (González Ruibal, 2004a: 40-41).

\section{SANTUARIOS Y PRESENCIA COLONIAL EN FINISTERRE}

Nos parece especialmente relevante el reciente descubrimiento de varios betilos en Museo del Mar y Toralla, tratándose de enclaves situados muy próximos desde el punto de vista geográfico puesto que ambos controlan la entrada a la ría de Vigo (González Ruibal, 2004a: 41; 2006: 139; Domínguez Pérez, 2006: 53). El primero fue abandonado hacia el siglo IV a.C., en tanto el segundo estuvo en uso al menos durante los siglos VI-V a.C., sin que por ahora pueda establecerse una relación de contemporaneidad o continuidad entre estos yacimientos. En Museo del Mar se han recuperado tres betilos, aun cuando no se descarta que en un principio pudieran ser cuatro, siendo uno solo el constatado en Toralla (González Ruibal, 2005: 139). Este número de betilos impar, tres en un lugar y uno en otro, cuadra bastante bien con lo que solemos hallar en el ámbito fenicio, tanto si nos referimos a las representaciones grabadas en estelas en Cartago o Mozia donde aparecen uno o tres betilos (Moscati 1988: 
368-370), como a piezas de tamaño natural según se advierte en el denominado santuario B de Kommos en la isla de Creta en el que sobre una plataforma se colocaron también tres betilos (Shaw, 1998: 9-11).

La presencia de betilos, que recordemos en el ámbito fenicio viene a ser una imagen de culto en sí misma pues en su interior se encuentra la divinidad (Moore, 1903; 198-199; Seco Sierra, 1999: 136-137), nos remite a lugares cultuales propios del mundo religioso fenicio que se hallan inmersos en asentamientos indígenas, de tal manera que nos encontramos ante unos elementos que responden a modelos bien conocidos en el ámbito colonial oriental. Como es sabido estos centros, que a veces como ocurre en el templo maltés de Tas Silg reutilizan estructuras indígenas megalíticas preexistentes (Vidal González, 2000: 117-118), cobran un papel fundamental en el seno de la actividad comercial fenicia como lo acreditan los casos de Creta y Chipre, donde las únicas instalaciones fenicias constatadas en ambas islas corresponden a este tipo de edificaciones según vemos desde las últimas décadas del siglo IX a.C., la misma época en la que en el asentamiento peninsular de Ratinhos se construyó un templo de carácter oriental inserto en esta comunidad indígena (Prados Martínez, 2010: 265-270).

En este sentido conviene tener presente el papel que tuvieron los templos y santuarios en el marco del proceso colonial fenicio pues, además de su lógica faceta religiosa, jugaban un importante papel como centros económicos en los que se llevaban a cabo actividades artesanales, a la par que preservaban conocimientos muy útiles de cara a la navegación sin olvidar su vertiente política al estar vinculados a la acción del estado (Ruiz de Arbulo Bayona, 1997: 520523; Fumadó Ortega, 2012: 15-28). Parece bastante probable que el templo de Melqart jugara un importante papel en este proceso (González Ruibal et alii, 2007: 86), siendo sintomática la aparición de miles de fragmentos cerámicos fenicios en el yacimiento de Museo del Mar, en su mayoría pertenecientes a ánforas Mañá-Pascual A4 (González Ruibal, 2005: 139), lo que nos sugiere la existencia de un probable almacén vinculado al santuario.

La construcción de santuarios fenicios en esta zona nos obliga a plantearnos la posible presencia directa de algún componente poblacional de carácter oriental, y que se ha valorado pudo tener un carácter temporal (Suárez Otero, 2004: 40 ), el cual resulta imposible de cuantificar por ahora y viviría inmerso en un contexto poblacional indígena. En realidad es ésta una idea que ya se había sugerido para algunos castros en los que el volumen de material mediterráneo sobrepasaba con mucho lo que suele ser habitual, como vemos en Montealegre donde se tomaba como referente las presencia de contenedores y cerámicas de cocina (González Ruibal et alii, 2002: 69-70; Ayán Vila et alii, 2007: 87-88), así como los castros de A Lanzada y Museo del Mar (González Ruibal, 2006: 
139 y 146), sobre todo si tenemos presente la aparición en este último yacimiento de un santuario y unos 2000 fragmentos cerámicos de adscripción oriental. Además, algunos estudiosos (Castro Pérez, 1999: 375) han planteado la posible presencia de artesanos fenicios que habrían enseñado sus técnicas de trabajo a los orfebres galaicos. En todo caso pensamos que esta presencia directa no debió ser muy numerosa desde el punto de vista cuantitativo, ya que solamente sería necesario disponer de unos pocos comerciantes, así como algunos orfebres si admitimos esta hipótesis, resultando quizás más claro en el caso de los santuarios detectados que indudablemente debían contar con algunos sacerdotes y/o sacerdotisas como personal dedicado a llevar a cabo las prácticas rituales y religiosas que se debían realizar en ellos.

\section{IMPLICACIONES HISTÓRICAS DE LA INFLUENCIA FENICIA}

La actividad fenicia puso en contacto una serie de redes comerciales atlánticas, que en muchos casos existían con anterioridad a su llegada, con las del Mediterráneo (Guerrero Ayuso, 2009: 71). Este comercio, que en absoluto estuvo controlado por Cartago como a veces se ha planteado, se vincula directamente con las colonias del sur peninsular a juzgar por la naturaleza del registro arqueológico documentado hasta el momento (Coelho, Marcelo, 2001: 233; González Ruibal, 2004b: 299-300; 2006: 128). En el mismo el papel jugado por Cádiz parece haber sido bastante destacado tanto en lo concerniente a la comercialización de los productos propios del elenco fenicio, ya pertenezcan al Círculo del Estrecho o al área ibicenca, o se trate de otros de raigambre helena o inclusive indígena, bien sea ésta ibérica o turdetana (Millán León, 1998: 167-168; Guerrero Ayuso, 2009: 70-71; Domínguez Pérez, 2011: 259).

La posterior conquista romana no parece haber supuesto para esta ciudad una sustancial pérdida de influencia sino que, antes al contrario, Cádiz asume un rol destacado pues no olvidemos que, como recoge Estrabón (Geog., III, 3, 5), los romanos conocieron esta ruta hacia el norte gracias a los marinos gaditanos y que su papel fue fundamental en la campaña que Julio César llevó a cabo en esta zona (Millán León, 1998: 189; Seco Sierra, 1999: 363-367), siendo también de esta misma procedencia algún hallazgo localizado aún más al norte como puede ser una moneda de esta ceca encontrada en York (Alfaro Asins, 1988: 87). En relación con lo expuesto está también el hecho de que Cádiz haya sido propuesta como centro redistribuidor durante los siglos $\mathrm{V}$ y IV a.C. de las cerámicas griegas que llegaban allí desde Ampurias (Cabrera Bonet, 1994: 96-98), lo que explicaría bastante bien la aparición en estas latitudes de cerámicas ibéricas de la zona levantina y catalana, ya que era en esta colonia helena donde los gaditanos las obtenían (Sanmartí Greco, 1999: 170-172). 
Ahora bien, si este comercio fue controlado por Cádiz, o de forma más genérica por los asentamientos fenicios que podemos vincular con el Círculo del Estrecho (Arruda, 2002: 260), ¿cómo debemos interpretar entonces el conocido periplo de Himilcón? Se ha propuesto que la motivación de este viaje no fue otra que el deseo por parte de Cartago de acceder a las fuentes del estaño atlántico (Wagner, 1983: 228; Frutos Reyes, 1991: 147), algo que resulta lógico y al que también podríamos sumar el oro galaico. Sin embargo, la veracidad de los hechos relatados tan sumariamente por Plinio el Viejo (Hist. Nat., II, 169) y Avieno (Or. M., 117-130, 380-390 y 412-414) dista mucho de ser aceptada por todos, puesto que si para algunos autores ambos se basan en fuentes más antiguas, ya sean éstas griegas del siglo VI a.C. (Schulten, 1979: 110-113) o fenicias de la primera mitad del siglo VII a.C. (Alvar Ezquerra, 1999: 361363), también hay quien piensa que la fuente primigenia no es otra que el relato de un oficial romano que nunca habría visitado la zona que describe (Frankenstein, 1997: 154). Aun así, y con independencia de la veracidad que otorguemos a este texto, el problema básicamente sigue siendo, al igual que acontece con el periplo de Hannón para las costas norteafricanas, que el registro arqueológico no avala en absoluto una preponderancia cartaginesa que queda reducida a unos cuantos recipientes anfóricos, sino relacionada directamente con el mediodía peninsular, por lo que cabría admitir que, o bien el pretendido intento de eliminar cualquier intermediario, en especial el gaditano, resultó una empresa a la postre fallida para Cartago (Alvar Ezquerra, 1999: 368), o la realidad histórica de lo acaecido se ha visto sustancialmente alterada en unas fuentes muy alejadas temporalmente de la etapa que narran.

Resulta difícil valorar por el momento si estos contactos crearon a la postre diferencias regionales tal y como sucedió en otras zonas periféricas a las que también llegó esta presencia orientalizante, como pueden ser Portugal (Arruda, 2002: 258) y Extremadura (Celestino, 2001: 112). No obstante, lo más probable es que los mayores beneficiados fuesen los sectores dirigentes de las poblaciones indígenas (González Ruibal, 2004: 294), sobre todo las de algunos puntos costeros, pero sin que parezcan existir modificaciones sustanciales en otros aspectos que nos permitan hacerlo generalizable siendo sintomático que estos materiales foráneos no aparezcan en sus enterramientos. Sí parece claro que la introducción de las cuentas de collar de pasta vítrea en un buen número de yacimientos del interior, y no sólo de la franja litoral como suele ser habitual (Paz Virvet, 2016: 130), nos demuestra que fueron unos elementos bastante apreciados, algo que creemos se debe no sólo a su carácter de objeto de adorno exótico, sino sobre todo al papel mágico que jugaron en la Antigüedad como amuleto destinado a proteger contra el mal de ojo (Vázquez Hoys, 2000: 57-60). 
Aunque se ha plantado que la producción de objetos de hierro pudo provocar un cambio sustancial en estas comunidades (Hidalgo Cuñarro, Peña Santos, 2000: 810), pensamos que tal aseveración puede ser excesiva puesto que los instrumentos que vemos hechos en hierro son muy escasos, ya que apenas se puede mencionar el castro de Torroso donde se halló una hoz de este metal datada a finales del siglo VII a.C., así como algunos punzones, barritas y puñales de origen céltico (Peña Santos, 1988: 352-353; Camino Mayor, Villa Valdés, 2016: 61-62).

Este intercambio de bienes se inserta perfectamente en el denominado comercio desigual, bien conocido en distintos contactos establecidos entre varias sociedades de la Antigüedad, comercio que queda caracterizado porque sus mecanismos son en última instancia controlados por aquella parte que goza de un mayor desarrollo tecnológico, en este caso los fenicios, y a través del cual obtiene valiosas materias primas a cambio de productos manufacturados (Wagner, 2001-35-36). Ahora bien, ello no significa que los habitantes de estos territorios hubieran de sentirse descontentos o engañados por estas transacciones, sino que, desde nuestro punto de vista, los fenicios venían a reproducir en estas latitudes un modelo que ya con tanto éxito habían llevado a cabo en los dos extremos del Mediterráneo, es decir, poner en contacto dos esferas económicas jugando con las diferencias de precios que en ellas tenían determinados productos (Gómez Crespo, 1993: 25-29; Aubet Semmler, 2007: 390-392).

Algunos autores han sugerido que varios asentamientos, como pueden ser los castros de Toralla, Neixón y Punta de Muio en la ría de Vigo y A Lanzada en la de Pontevedra, habrían funcionado como auténticos emporios y centros redistribuidores (González Ruibal, 2004b: 144; Ayán Vila et alii, 2007: 193; González Ruibal et alii, 2010: 589-590; Paz Virvet, 2016: 130). Ello significa que los fenicios obtenían los productos que precisaban de estos centros indígenas, lo que confiere un especial protagonismo a sus elites dirigentes al ser ellas las que controlan y pueden facilitarles los recursos del interior al que los fenicios no acceden. Este hecho explicaría las evidencias que nos hablan de la existencia de banquetes en los que se consumía alcohol (González Ruibal, 2004: 40; Paz Virvet, 2016: 139), lo que cuadra muy bien con el contenido de los kalathos levantinos documentados ya que estos habrían contenido miel, la cual se empleaba para la condimentación del vino, y que se han relacionado con prácticas de carácter aristocrático (Camuña Pardo, 2016: 40-41). Máxime si tenemos en consideración que también por parte fenicia estas navegaciones eran controladas por los aristócratas y ricos comerciantes, quienes se podían permitir los elevados gastos que conllevaba fletar un navío (Alvar Ezquerra, 2001: 73-74; Martín Ruiz, 2010: 135-136). 


\section{CONCLUSIONES}

Es posible apreciar cómo el factor oriental comienza a valorarse a la hora de examinar la evolución histórica de estas poblaciones norteñas, siendo más notable y antiguo de lo que hasta no hace mucho se pensaba, de manera que empieza a apreciarse como algo más que un elemento exótico ya que aparece imbricado en el desarrollo histórico de esta zona, siendo una continuidad de los contactos establecidos con la zona portuguesa (Coelho Ferreira da Silva, Mendez Pinto, 2001: 234), de tal manera que se confirma que el Mondego no fue en absoluto un límite natural para estas navegaciones atlánticas (Domínguez Pérez, 2006: 54; 2011: 258).

Aunque la fecha más antigua documentada hasta el momento por lo general no va más allá del siglo VI a.C., con un notable incremento en las centurias siguientes, la influencia que se advierte sobre la orfebrería castreña, la presencia de estaño de esta zona en el pecio de Bajo de la Campana, así como la aparición de objetos de hierro o algún fragmento cerámico que pudiera llevarse hasta un siglo VII a.C. retrasarían estos influjos hasta época arcaica. Ciertamente la evidencia material es bastante escasa para estos momentos, aunque si examinamos la temprana cronología que ofrece la presencia fenicia en las costas portuguesas (Arruda, 2002: 257) no debería extrañarnos que en el futuro aparezcan nuevas evidencias de estas fechas, máxime si tenemos en mente la notable expansión que experimenta el comercio del Círculo del Estrecho desde el siglo VII a.C. hacia el levante peninsular e Ibiza, el norte de África y la fachada atlántica portuguesa (Aubet Semmler, 1995: 234-239).

No obstante, como decimos la mayoría de los restos descubiertos se sitúan a partir del siglo VI a.C., cuando disminuye el comercio de corte aristocrático basado en la transacción de bienes de prestigio y se incrementa el de alimentos y otros bienes que se distribuyen a un nivel socioeconómico mucho más amplio que el anterior (Martín Ruiz, 2007: 144-146). Sin embargo, no por ello hemos de pensar que dejaron de comercializarse bienes que cabe vincular con los sectores dirigentes de estas comunidades norteñas, ya que recientemente se ha sugerido que los kalathos elaborados en alfares del nordeste peninsular estaban destinados a almacenar miel que era empleada en la preparación de vino, y vinculados por tanto con elementos aristocráticos a los que también iban dirigidos los vasos griegos (Camuña Pardo, 2016: 40-45). A tenor de lo visto existe una amplia continuidad con la conquista romana, siendo especialmente notable el comercio de vinos, bebida con la que también podemos vincular las escasas páteras campanienses localizadas. 
En este comercio el papel jugado por Cádiz debió ser bastante importante, aunque a veces se tiende a minusvalorar el que pudieron tener otros centros coloniales, el cual se incrementa incluso con la conquista romana y sin que el peso de Cartago parezca ser muy importante, si bien da la impresión de estar centrado sobre todo en puntos próximos al litoral decreciendo notablemente en intensidad a medida que progresamos hacia el interior. El principal interés desde el punto de vista de los fenicios habría sido sobre todo la obtención de metales, particularmente el estaño aunque tampoco debemos olvidar el oro, a lo que también podríamos añadir otros productos como esclavos, pieles, etc., en tanto las comunidades indígenas recibirían a cambio alimentos como vino, miel y salazones de pescado, sal, objetos de bronce, perfumes, recipientes cerámicos, joyas, amuletos y, tal vez, vestimentas.

Pensamos que, al igual que acontece en otros ámbitos peninsulares, estas poblaciones norteñas llevaron a cabo una aceptación selectiva del bagaje cultural foráneo, aceptando sólo aquello que pudiera favorecerles, en particular a sus sectores dominantes. Queda claro que durante varios siglos los fenicios aparecen como los principales abastecedores de un buen número de productos, lo que ha abierto el debate acerca de si hubo individuos procedentes del sur conviviendo con los autóctonos de la zona, algo que la reciente localización de posibles lugares de culto hace bastante plausible.

En definitiva, podemos concluir afirmando que los descubrimientos efectuados en los últimos años en el noroeste peninsular vienen a acabar definitivamente con una visión, a veces demasiado arraigada en la historiografía, según la cual estos territorios habrían permanecido en un relativo aislamiento del exterior, sobre todo en lo concerniente a posibles contactos con el mundo mediterráneo al menos hasta su conquista por Roma, algo que ya no es posible seguir manteniendo, de manera que las futuras investigaciones habrán de dilucidar no si estos contactos tuvieron lugar sino el grado de intensidad que alcanzaron.

\section{BIBLIOGRAFÍA}

ALFARO ASINS, C. (1988): Las monedas de Gadir/Gades, Madrid, Fonumis.

ALMAGRO GORBEA, M. (2001): "El arte celta en la Península Ibérica", en M. ALMAGRO-GORBEA, M. MARINÉ, J. R. ÁLVAREZ (Eds.). Celtas y Vettones, Ávila, Diputación Provincial, pp. 159-170.

ALVAR EZQUERRA, J. (1980): "El comercio del estaño atlántico durante el período Orientalizante", Memorias de Historia Antigua, IV, pp. 43-49.

ALVAR EZQUERRA, J. (1999): "Los fenicios en Occidente", en Fenicios y cartagineses en el Mediterráneo, Madrid, editorial Cátedra, pp. 313-450. 
ALVAR EZQUERRA, J. (2001): “La navegación en el desarrollo de las relaciones de dependencia", en J. L. LÓPEZ CASTRO (Ed.). Colonos y comerciantes en el Mediterráneo, Almería, Universidad de Almería, pp. 71-86.

ARRUDA, A. M. (2002): Los fenicios en Portugal. Fenicios y mundo indígena en el centro y sur de Portugal (siglos VIII-VI a.C.), Barcelona, Universitat Autónoma.

AUBET SEMMLER, $\mathrm{M}^{\mathrm{a}}$ E. (1995): "El comercio fenicio en Occidente". En I fenici: ieri, oggi, domani, Roma, Bompiani, pp. 227-243.

AUBET SEMMLER, $\mathrm{M}^{\mathrm{a}}$ E. (2007): Comercio y colonialismo en el Próximo Oriente antiguo. Los antecedentes coloniales del III y II milenios a. C., Barcelona, editorial Crítica.

AVIENO, R. F. (2001): Fenómenos. Descripción del orbe terrestre. Costas Marinas, trad. J. C. Felices, Madrid, editorial Gredos.

AYÁN VILA, X. M., RODRÍGUEZ MARTÍNEZ, R. Mª, GONZÁLEZ RUIBAL, A., GÓNZÁLEZ PÉREZ, L., ARIZAGA CASTRO, A., FRANCO FERNÁNDEZ, L. (2007): "Un espacio monumental de la $2^{\mathrm{a}}$ edad del Hierro: el acceso SE al recinto superior de O Castro Grande de Neixón (Boio, A Coruña)", en A. FANJUL PERAZA (Coord.). Estudios varios de arqueología castreña. A propósito de las excavaciones en los castros de Teverga (Asturias), Santander, Ayuntamiento de Teverga, pp. 189-209.

AYÁN VILA, X. M., RODRÍGUEZ MARTÍNEZ, R. Ma , GÓNZÁLEZ PÉREZ, L., GONZÁLEZ RUIBAL, A. (2008): “Arrecendos púnicos: un novo anaco de aríbalos no castro Grande de Neixón (Boiro, A Coruña)", Cuadernos de Estudios Gallegos, LV, pp. 73-92.

CABRERA BONET, P. (1994): “Cádiz y el comercio de productos griegos en Andalucía occidental durante los siglos V y IV a.C.”, Trabajos de Prehistoria, 51, 2, pp. 99-101.

CAMINO MAYOR, J., VILLA VALDÉS, A. (2004): “La bahía de Gijón y las rutas marítimas prerromanas en la costa cantábrica de la Península Ibérica”, en C. FERNÁNDEZ OCHOA (Coord.). Gijón puerto romano. Navegación y comercio en el Cantábrico durante la Antigüedad, Gijón, Autoridad Portuaria de Gijón, pp. 45-59.

CAMINO MAYOR, J., VILLA VALDÉS, A. (2014): "El hierro en registro arqueológico de la protohistoria cantábrica", Kobie Anejos 13, pp. 59-74.

CAMINO MAYOR, J., VILLA VALDÉS, A. (2016): “Acerca de la antigüedad del castro de Coaña (Asturias): las dataciones Carbono 14", Férvedes, 8, pp. 209-214.

CAMUÑA PARDO, D. (2016): "Els càlats ibèrics, una forma cerámica tardana (segles III-I a.C.) lligada a l'aristocràcia?. Els exemples de Fontscaldes i el Vilar", Quaderns de Vilaniu, 69, pp. 25-48.

CARBALlO ARCEO, X., CONCHEIRO COELLO, A., REY CASTIÑEIRA, J. (2003): "A introducción dos muíños circulares nos castros galegos", Brigantium, 14, pp. 97-108.

CASTRO PÉREZ, L. (1994): “Aportaciones púnicas a la orfebrería castreña”, en A. GONZÁLEZ BLANCO, J. L. CUNCHILLOS, M. MOLINA MARTOS (Eds.). El mundo púnico. Historia, sociedad y cultura, Murcia, Universidad de Murcia, pp. 371-385. 
CELESTINO, S. (2001): Extremadura tartésica. Arqueología de un proceso periférico, editorial Crítica, Barcelona.

COELHO FERREIRA DA SILVA, A. y MENDES PINTO, J. M. (2001): “Comércio púnico com o noroeste”, en Os púnicos no extremo ocidente, Lisboa, Universidade Aberta, pp. 229-238.

CORNIDE DE FOLGUEIRA, J. (1790). Las Casitérides, o Islas del Estaño, restituidas a los mares de Galicia, Madrid.

DOMÍNGUEZ PÉREZ, J. C. (2005a): "Materiales púnico-gaditanos en los confines del extremo occidente atlántico", Antiquitas, 17, pp. 5-11.

DOMÍNGUEZ PÉREZ, J. C. (2005b): “Gallaecia Poena. Avance para una definición no esencialista del Hierro Final noroccidental", Gallaecia, 24, pp. 35-60.

DOMÍNGUEZ PÉREZ, J. C. (2006): "La ruta púnica hacia el extremo occidente noratlántico", Gallaecia, 25, pp. 45-63.

DOMÍNGUEZ PÉREZ, J. C. (2011): “Hippoi en los confines del mundo: los límites noratlánticos de la talasocracia de Gadir”. En J. C. DOMÍNGUEZ PÉREZ (Ed.). Gadir y el Círculo del Estrecho revisados. Propuestas de la arqueología desde un enfoque social, Cádiz, Universidad de Cádiz, pp. 283-303.

FERNÁNDEZ URIEL, P. (2000): “El comercio de la púrpura”, en P. FERNÁNDEZ URIEL, C. GONZÁLEZ WAGNER, F. LÓPEZ PARDO (Eds.). Intercambio y Comercio Preclásico en el Mediterráneo, Madrid, CEFYP, pp. 271-279.

FERREIRO LÓPEZ, M. (1988): “La campaña militar de César en el año 61”, en G. PEREIRA MENAUT (Ed.). Actas del I Congreso Peninsular de Historia Antigua, Santiago de Compostela, Universidad de Santiago, vol. II, pp. 363-372.

FRANKESNSTEIN, S. (1997): Arqueología del colonialismo. El impacto fenicio y griego en el sur de la Península Ibérica y el suroeste de Alemania, Barcelona, editorial Crítica.

FRUTOS REYES, G. DE (1991): Cartago y la política colonial. Los casos norteafricano e hispano, Écija, Gráficas Sol.

FUENTES ESTAÑOL, M ${ }^{\mathrm{a}}$ J. (1986): Corpus de las inscripciones fenicias, púnicas y neopúnicas de España, Barcelona.

FUMADÓ ORTEGA, I. (2012): “Aspectos marítimos de las divinidades fenicio-púnicas como garantía de la confianza de los mercados", en E. FERRER, M. C. MARÍN, A. PEREIRA (Coords.). La religión del mar. Dioses y ritos de navegación en el Mediterráneo antiguo, Sevilla, Universidad de Sevilla, pp. 11-36.

GARCÍA Y BELLIDO, A. (1980): España y los españoles hace dos mil años según la Geografía de Strabón, $7^{\mathrm{a}}$ ed., Madrid, Espasa Calpe.

GÓMEZ CRESPO, P. (1993): Comprar y vender. La cultura del comercio y del mercado, Madrid, Eudema.

GONZÁLEZ RUIBAL, A. (2004a): "Un askós ibicenco en Galicia: notas sobre el carácter del comercio púnico en el noroeste ibérico", Complutum, 15, pp. 33-43.

GONZÁLEZ RUIBAL, A. (2004b): "Facing two seas: mediterranean and atlantic contacs in the north-west of Iberia in the first millennium b. C.", Oxford Journal of Archaeology, 23, 3, pp. 287-317. 
GONZÁLEZ RUIBAL, A. (2006): "Past the Last Ouspost: Punic Merchants in the Atlantic Ocean (5 th.-1 st centuries BC)", Journal of Mediterranean Archaeology, 191, pp. 121-150.

GONZÁLEZ RUIBAL, A., RODRÍGUEZ MARTÍNEZ, R., ABOAL FERNÁNDEZ, R, CASTRO HIERRO, V. (2007): "Comercio mediterráneo en el castro de Montealegre (Pontevedra, Galicia). Siglo II a.C.-inicios del I d.C.”, Archivo Español de Arqueología, 80, pp. 43-74.

GONZÁLEZ RUIBAL, A., RODRÍGUEZ MARTÍNEZ, R., AYAN VILA, X. (2010): "Buscando a los púnicos en el noroeste", Mainake, XXXII, pp. 518-600.

GROSSI MAZZORIN, J. DE (2008): “L'uso dei cani nel mondo antico nei riti di fondazione, purificazione e passagio”, en F. D’ANDREA, J. DE GROSS, G. FLORENTINO (Eds.). Uomini piante e animale nella dimensione del sacro, Bari, Edipuglia, pp. 71-81.

GUERRERO AYUSO, V. M. (2009): “Las naves de Kerné (II). Navegando por el Atlántico durante la protohistoria y la antigüedad", en R. GONZÁLEZ ANTÓN, F. LÓPEZ PARDO, V. PEÑA ROMO (Eds.). Los Fenicios y el Atlántico, CEFYP, Madrid, pp. 69-142.

HIDALGO CUÑARRO, J. M., PEÑA SANTOS, A. DE LA (2000): "Los contactos entre el área galaica y el Mediterráneo durante la prehistoria reciente”, en M. E. AUBET, M. BARTHÉLEMY (Eds.). Actas del IV Congreso Internacional de Estudios Fenicios y Púnicos, Universidad de Cádiz, Cádiz, vol. II, pp. 807-813.

HÜBNER, E. (1902): “Galicia histórica y prehistórica”, Boletín de la Real Academia de la Historia, 40, pp. 547-553.

JÁUREGUI, J. J. DE (1952): La carrera del estaño en la Ora Marítima de Avieno, Madrid, CSIC.

LADRA FERNÁNDEZ, X. L. (1999): “Análisis ponderal de los torques castreños”, Complutum, 10, pp. 143-156.

LÓPEZ PARDO, F. (2000): El empeño de Herakles. (La exploración del Atlántico en la Antigüedad), Madrid, Arco/Libros.

MACIÑEIRA PARDO, F. (1896): "Los fenicios en Galicia”, La Ilustración Española y Americana, XXXII, Madrid, pp. 123 y 126.

MARÍN SUÁREZ, C. (2007): "Los materiales del castro de San L. Luis (Allande, Asturias)", Complutum, 18, pp. 131-160.

MARTÍN RUIZ, J. A. (2003): La crisis del siglo VI a.C. en los asentamientos fenicios de Andalucía, Málaga, Cedma.

MARTÍN RUIZ, J. A. (2010): "El comercio cananeo y fenicio a través del cargamento transportado en los pecios hallados en el Mediterráneo", Revista Atlántica-Mediterránea de Arqueología Social, 12, pp. 127-138.

MARTÍN RUIZ, J. A. (2013): "Barcos mercantes fenicios en el Mediterráneo occidental", Revista de Historia Naval, 121, pp. 37-53.

MEDEROS MARTÍN, A., RUIZ CABRERO, L. A. (2004): “El pecio fenicio del Bajo de la Campana (Murcia, España) y el comercio de marfil norteafricano", Zephyrus. Revista de Prehistoria y Arqueología, 57, pp. 263-281. 
MILLÁN LEÓN, J. (1998): Gades y las navegaciones oceánicas en la Antigüedad (1000 a. C.-500 d. C.), Écija, Gráficas Sol.

MOORE, G. F. (1903): "Baetylia”, American Journal of Archaeology, 7, 2, pp. 198-208. MOSCATI, S. (1988): "Le stele”, en S. MOSCATI (Ed.). I fenici, Milano, Bompiani, pp. 364-379.

NIVEAU DE VILLEDARY Y MARIÑAS, A. M (2008): “¿Compañero en la muerte o guía hacia el más allá?. El perro en la liturgia funeraria púnica”, en E. FERRER ALBELDA, J. MAZUELO PÉREZ, J. L. ESCACENA CARRASCO (Coords.). De dioses y bestias. Animales y religión en el Mundo Antiguo, Sevilla, Universidad de Sevilla, pp. 94-137.

PARCERO-OUBIÑA, C., GARCÍA-VUELTA, O., ARMADA, X. L. (2009): “Contexto y tecnologías de la orfebrería castreña: en torno a una nueva arracada de Punta dos Prados (Espasante. Ortigueira, A Coruña)", Complutum, 20, 1, pp. 83-108.

PAZ VIRVET, A. I. (2016): “Contactos comerciales entre las culturas púnica y castreña de la Península Ibérica en la Edad del Hierro. Investigación arqueológica realizada y estado de la cuestión", en R. CORDEIRO MACENLLE, A. VÁZQUEZ MARTÍNEZ (Eds.). Estudos de arqueoloxia, prehistoria e historia antiga, Santiago de Compostela, Torculo Ediciones, pp. 125-142.

PELLICER CATALÁN, M. (1998): “La colonización fenicia en Portugal y la orientalización del Occidente de la Península Ibérica”, en Veröff. Joachim Jungius Ges. Wiss, Hamburg, pp. 531-538.

PEÑA SANTOS, A. (1988): "Metalurgia galaica en la transición Bronce-Hierro: el castro de Torroso", Espacio, Tiempo y Forma, I, pp. 339-360.

PÉREZ OUTERIÑO, B. (1989): “Orfebrería castreña”, en El oro en la España prerromana, Madrid, Zugarto Ediciones, pp. 90-107.

PÉREZ PÉREZ C., PORTO TENDEIRO, Y., TORRE CASTRO, C. (2010): “Conxunto de doas de pasta vítrea do Museo do Castro de Viladonga", Boletín de la Asociación de Amigos do Castro de Viladonga, 20, pp. 50-63.

PLINIO EL VIEJO (2002): Historia Natural, trad. J. Cantó, I. Gómez, S. González y E. Tarriño, Madrid, editorial Gredos.

POLZER, M. E. (2014): "The Bajo de la Campana Shipwreck and colonial trade in Phoenician Spain", en J. ARUZ, S. B. GRAF, Y. RAKIC (Eds.). Assyria to Iberia at the Dawn of the Classsical Age, New York, Metropolitan Museum of New York, pp. 230-242 y 369-370.

PRADOS MARTÍNEZ, F. (2010): "La arquitectura sagrada: un santuario del siglo IX a.C.”, en L. BERROCAL-GANGEL, A. CARLOS SILVA (Eds.). O castro dos Ratinhos (Barragem do Alqueva, Moura): escavaçöes num povoado proto-historico do Guadiana, Lisboa, Museu Nacional de Arqueología, pp. 259-276.

RAMÓN TORRES, J. (2006): “La proyección comercial mediterránea y atlántica de los centros fenicios malagueños en época arcaica”, Mainake, XXVIII, pp. 189-212.

RUIZ DE ARBULO BAYONA, J. (1997): "Santuarios y comercio marítimo en la Península Ibérica durante la época arcaica", Quaderns de Prehistòria i Arqueología de Castelló, 18, pp. 517-534. 
RUIZ-GÁLVEZ PRIEGO, M. (1986): “Navegación y comercio entre el Atlántico y el Mediterráneo a fines de la Edad del Bronce", Trabajos de Prehistoria, 43, pp. 9-42. RUIZ-GÁLVEZ PRIEGO, M. (2005): "Representaciones de barcos en el arte rupestre: piratas y comerciantes en el tránsito de la Edad del Bronce a la Edad del Hierro", Mayurqa, 30, pp. 307-340.

RUIZ ZAPATERO, G. (2003): "Historiografía y uso público de los celtas en la España franquista”, en F. WULFF ALONSO, M. ÁLVAREZ MARTÍ-AGUILAR (Eds.). Antigüedad y franquismo (1936-1975), Málaga, Cedma, pp. 217-240.

SANMARTÍ GRECO, E. (1999). “Observaciones acerca de las relaciones económicas entre el mundo foceo del nordeste y el sur peninsulares en los siglos V y IV a.C.", Anejos Archivo Español de Arqueología, XX, pp. 167-174

SCHULTEN, A. (1979). Tartessos, $2^{\mathrm{a}}$ ed., Madrid, Espasa Calpe,

SECO SERRA, I. (1999): "El betilo estiliforme de Torreparedones", Spal. Revista de Prehistoria y Arqueología, 8, pp. 135-158.

SHAW, J. W. (1998): "Kommos in Southern Crete: an Aegean Barometer for EastWest Interconnections", en V. KARAGEORGHIS. N. STAMOPOLIDIS (Eds.). Eastern Mediterranean: Cyprus-Dodecanese-Crete 16 th-6 th cent. B. C., Athens, University of Crete, pp. 2-17.

SUÁREZ OTERO, J. (2004): "Cipo de Toralla y posible altar púnico de Alcabre, siglos V-II a.C.”, en Hasta el confín del mundo: diálogos entre Santiago y el mar, Vigo, Xunta de Galicia, p. 40.

SUÁREZ OTERO, J., FARIÑA BUSTO, F. (1990): “A Lanzada (Sanxenxo, Pontevedra), definición e interpretación de un yacimiento castreño atípico. Apuntes para un estudio de los intercambios protohistóricos en la costa atlántica peninsular", Madrider Mitteilungen, 31, pp. 309-337.

VÁZQUEZ HOYS, A. Ma (2000): "La magia de las cuentas y de los colgantes de vidrio fenicios", en E. RUANO RUIZ, P. PASTOR REY DE VIÑAS, R. CASTELO RUANO (Eds.). Joyas prerromanas de vidrio, Madrid, Centro Nacional del Vidrio, pp. 53-75.

VIDAL GONZÁLEZ, P. (2000): “El papel del templo de Tas Silg. Fenicios e indígenas en Malta”, en P. FERNÁNDEZ URIEL, C. GONZÁLEZ WAGNER, F. LÓPEZ PARDO (Eds.). Intercambio y Comercio Preclásico en el Mediterráneo, Madrid, CEFYP, pp. 115-122.

WAGNER, C. (1983): Fenicios y cartagineses en la Península Ibérica: ensayo de interpretación fundamentado en un análisis de los factores internos y de los mecanismos de la colonización fenicio-púnica en Occidente, Madrid, Universidad Complutense.

WAGNER, C. (2001): “Comercio, colonización e interacción cultural en el Mediterráneo antiguo y su entorno. Ensayo de aproximación metodológica”, en J. L. LÓPEZ CASTRO (Ed.). Colonos y comerciantes en el Occidente mediterráneo, Almería, Universidad de Almería, pp. 13-56. 